\title{
Towards a coherent European approach for taxation of combustible waste
}

\author{
Dubois, M.
}

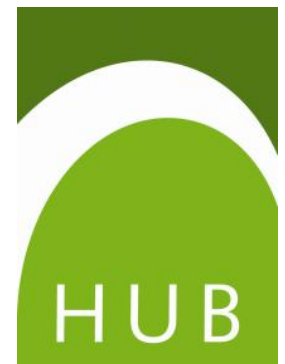




\title{
Towards a coherent European approach for taxation of combustible waste
}

\author{
M. Dubois
}

\begin{abstract}
Although intra-European trade of combustible waste has grown strongly in the last decade, incineration and landfill taxes remain heterogeneous within Europe. A review of taxation schemes in North Western Europe shows that current heterogeneity does not constitute a level playing field for waste processing industries in different regions. The paper proposes a more coherent taxation strategy for Europe that is based on the principle of Pigovian taxation. The strategy aims to create a level playing field between European regions while reinforcing incentives for sustainable management of combustible waste. Three important policy recommendations emerge. First, integrating waste incineration into the European carbon Emissions Trading System (EU ETS) reduces the risk of tax competition between regions. Second, because taxation of every single air pollutant from waste incineration is cumbersome, a differentiated waste incineration tax based on $\mathrm{NO}_{\mathrm{x}}$ emissions can serve as a second-best instrument. Finally, in order to strengthen incentives for ash treatment, a landfill tax should apply for landfilled incineration residues. An example illustrates the coherence of the policy recommendations for incineration technologies with diverse environmental effects.
\end{abstract}

